\title{
Effects of AZD3480 on Cognition in Patients with Mild-to-Moderate Alzheimer's Disease: A Phase IIb Dose-Finding Study
}

\author{
Lutz Frölich $^{\mathrm{a}, *}$, Tim Ashwood ${ }^{\mathrm{b}}$, Jonas Nilsson ${ }^{\mathrm{c}}$ and Göran Eckerwall ${ }^{\mathrm{b}}$, on behalf of the Sirocco \\ Investigators \\ ${ }^{a}$ Division of Geriatric Psychiatry, Central Institute of Mental Health, Medical Faculty Mannheim, \\ University of Heidelberg, Mannheim, Germany \\ ${ }^{\mathrm{b}}$ Clinical Neuroscience, AstraZeneca $R \& D$, Södertälje, Sweden \\ ${ }^{\mathrm{c}}$ Statistics \& Informatics, AstraZeneca $R \&$ D, Södertälje, Sweden
}

Handling Associate Editor: Sandrine Andrieu

Accepted 8 December 2010

\begin{abstract}
AZD3480 is a selective agonist of the central $\alpha 4 \beta 2$ and $\alpha 2 \beta 2$ neuronal nicotinic cholinergic receptors (NNRs). Its effects on cognition were investigated in 567 patients with mild-to-moderate Alzheimer's disease (AD) (Mini Mental State Examination [MMSE] 12-26). Mean baseline MMSE was 21 (SD \pm 3.7 ), with $61 \%$ of patients having mild disease (MMSE 21-26). Mean age was 74 (range 58-85) years. Patients were randomized to one of 5 treatment groups: AZD3480 $5 \mathrm{mg}, 20 \mathrm{mg}$ or 35/100 mg, donepezil $10 \mathrm{mg}$ (active comparator) or placebo, and treated once daily for 12 weeks. The primary outcome measure was change from baseline at Week 12 on the AD Assessment Scale-Cognitive Subscale (ADAS-Cog). Neither AZD3480 nor donepezil showed a statistically significant improvement versus placebo on ADAS-Cog. Improvements in a number of secondary outcome measures (MMSE, AD Cooperative Study-Clinical Global Impression of Change (ADCS-CGIC) and Disability Assessment for Dementia [DAD]) were observed for AZD3480 and for donepezil. A post-hoc analysis on ADAS-Cog, excluding patients with very mild AD (MMSE 25-26) indicated improvement versus placebo for AZD3480 $20 \mathrm{mg}(-1.4,95 \%$ CI: -3.0; $0.2)$ and donepezil $(-1.0,95 \% \mathrm{CI}:-2.3 ; 0.3)$. AZD3480 was well tolerated. The study did not meet proof of concept criteria, since neither AZD3480 nor donepezil were statistically significantly superior to placebo on ADAS-Cog and was considered to be inconclusive. Further studies are required to determine the therapeutic potential of stimulating $\alpha 4 \beta 2$ receptors with NNRs in AD patients.
\end{abstract}

Keywords: Alzheimer's disease, AZD3480, cognitive impairment, NNR agonist, randomized controlled trial

\section{INTRODUCTION}

Alzheimer's disease (AD) is a progressive neurodegenerative disease and the most common form of

\footnotetext{
${ }^{*}$ Correspondence to: Prof. Dr. Lutz Frölich, Head, Division of Geriatric Psychiatry, Central Institute of Mental Health, Medical Faculty Mannheim, University of Heidelberg, Square J 5, D-68159 Mannheim, Germany. Tel:: +49 6211703 3001; +49 6211703 3002 (Sec. Mrs. I. Schmitt); Fax: +49 6211703 3005; E-mail: lutz.froelich@zi-mannheim.de.
}

dementia in the elderly [1]. During the last two decades considerable research efforts have been directed towards identifying the cause of $\mathrm{AD}$, with the ultimate aim of developing safe and effective pharmacological treatments. Currently approved anti-dementia drugs consist of the acetycholinesterase inhibitors (AChEIs) donepezil, galantamine, and rivastigmine; and the N-methyl-D-aspartate (NMDA) antagonist, memantine. They provide symptomatic treatment of $\mathrm{AD}$ but their efficacy is modest and the disease continues 
to progress [1-3]. Furthermore, the cholinesterase inhibitors affect peripheral as well as central acetylcholinesterase resulting in side effects in the gastrointestinal, cardiovascular, and nervous systems [1], which limit their use at higher doses.

Research into the molecular pharmacology of central nervous system (CNS) nicotinic receptors has highlighted therapeutic possibilities for the development of novel nicotinic agents. Evidence from both animal and human studies supports the involvement of neuronal nicotinic cholinergic receptors (NNRs) in systems serving cognition [4]. NNRs are widely distributed throughout the CNS including structures known to be important for cognition such as the cerebral cortex, hippocampus, and thalamus [5]. They are known to modulate cognition in animals and humans [6] and there is evidence that they are altered in the brains of patients with disease-related cognitive deficits $[7,8]$. Among nicotinic receptor subtypes, the evidence is strongest for the involvement of the $\alpha 4 \beta 2$ and $\alpha 7$ subtypes in cognition [6]. The $\alpha 4 \beta 2$ subtype is only found in the CNS and is a prominent NNR subtype in the human brain [9]. Stimulation of this receptor regulates the release of several neurotransmitters known to be involved in cognition including glutamate, dopamine, acetylcholine, gamma-amino butyric acid (GABA), and noradrenaline [5, 10]. Activation also enhances hippocampal long-term potentiation, a synaptic strengthening associated with memory and learning $[11,12]$.

AZD3480 is a highly selective CNS-specific NNR agonist at the $\alpha 4 \beta 2$ NNR [13] and the co-localized $\alpha 2 \beta 2$ NNR [14]. It is devoid of activity at central $\alpha 7$ receptors and its very low activity on peripheral NNRs offers the potential for a low incidence of peripheral adverse events. AZD3480 has exhibited cognition-enhancing effects in non-clinical models of cognition [13]. It has also been shown to reverse fimbria fornix lesion-induced long-term potentiation deficits in rat hippocampal slice [14]. Moreover, AZD3480 has demonstrated an improvement on cognition in both healthy subjects and in phase II studies in patients with age-associated memory impairment (AAMI) and mild cognitive impairment (MCI) [15-20].

The objectives of this Phase IIb dose-finding study were to demonstrate that AZD3480 improves cognition in patients with mild-to-moderate $\mathrm{AD}$ relative to placebo and donepezil as an active comparator, to assess the dose relationship of three dose groups of AZD3480, and to assess safety and tolerability of AZD3480.

\section{METHODS}

\section{Study design/procedures}

This was a multicenter, double-blind, doubledummy, randomized, placebo-controlled, parallelgroup, Phase IIb study (Study NCT00501111). The study was approved by local ethics committees in all centers and was undertaken in compliance with the Declaration of Helsinki and according to the principles of Good Clinical Practice (GCP).

Patients were enrolled into the study from 84 participating centers across Europe (Austria, 3; Belgium, 4; Bulgaria, 7; Czech Republic, 14; Germany, 13; Romania, 6; Russia, 10; Spain, 12; United Kingdom, 6; and Canada, 9). They were prospectively genotyped with respect to their metabolism of CYP2D6 substrates and analyzed with respect to concomitant medication (AZD3480 is metabolized predominantly by this enzyme) and then classified as either rapid or slow metabolizers (RMs or SMs). RMs were defined as patients with $\geq 1.5$ functional CYP2D6 alleles who were not being treated concomitantly with any moderate or strong CYP2D6-inhibiting drug.

The study consisted of a 2 -week run-in period (no treatment), a 12-week treatment period and a 2-week follow-up period after administration of the last dose (Fig. 1). Patients were randomized to one of five treatment regimens: AZD3480 $5 \mathrm{mg}$, AZD3480 $20 \mathrm{mg}$, AZD3480 35/100 mg (i.e., $35 \mathrm{mg}$ for SMs [to limit exposure caused by the large variability] and $100 \mathrm{mg}$ for RMs), donepezil $5 \mathrm{mg}$, then $10 \mathrm{mg}$, or placebo. Randomization was stratified according to country, and to severity of dementia as measured by Mini Mental State Examination (MMSE 21-26 [mild] versus MMSE 12-20 [moderate]). Randomized treatments were administered once daily for 12 weeks in a doubledummy fashion with active treatment of AZD3480 administered in the morning and donepezil in the evening. All RM patients assigned to the $35 \mathrm{mg}$ dose group of AZD3480 had their dose increased to $100 \mathrm{mg}$ after 4 weeks' treatment and continued on this for the remainder of the study. Donepezil doses were chosen according to current label $(5 \mathrm{mg}$ once daily in the evening, which was then increased in all patients to $10 \mathrm{mg}$ after 4 weeks' treatment and continued for the remainder of the study).

\section{Patient eligibility}

Key inclusion criteria included: male or female, aged 60 to 85 years, with a clinical diagnosis of 


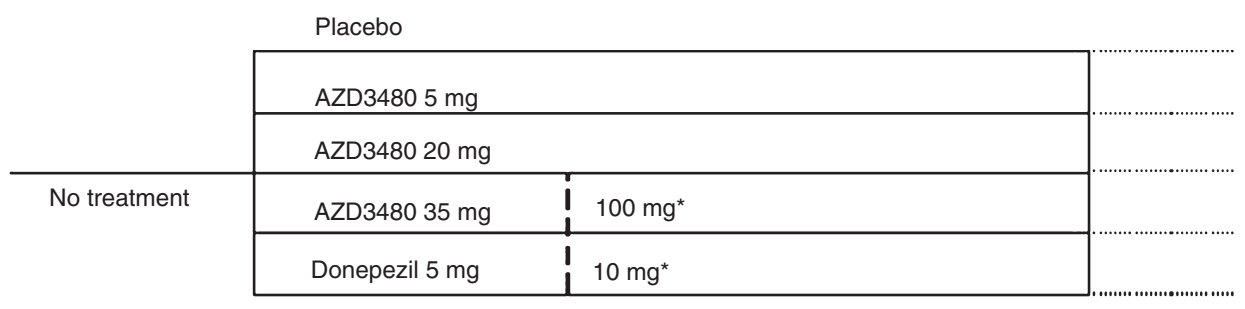

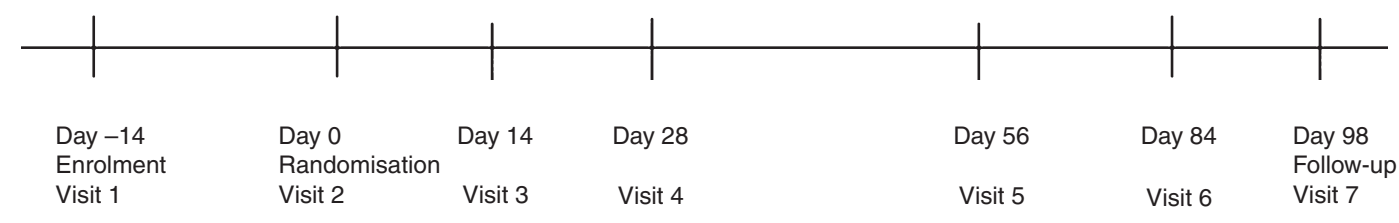

Fig. 1. Study design and sequence of treatment periods. *Dose increased only for rapid metabolisers.

probable $\mathrm{AD}$ according to National Institute of Neurological and Communicative Disorders and Stroke-Alzheimer's Disease and Related Disorders Association (NINCDS-ADRDA) criteria and with an MMSE score of between 12 and 26 (mild-to-moderate $\mathrm{AD})$; computerized tomography (CT) or magnetic resonance imaging (MRI) scan within the last 2 years (performed after onset of dementia) consistent with the diagnosis of $\mathrm{AD}$; a specified caregiver (at home, or in a community dwelling) capable of accompanying the patient on all clinic visits and visiting the patient $\geq 3$ times weekly for the study duration.

Key exclusion criteria included: use of AChEIs or memantine for treatment of AD within 8 weeks prior to enrolment and throughout the duration of the study (except investigational drug after randomization); use of smoking cessation therapy within 4 weeks of enrolment, or during the study; initiation or dose change of Ginkgo Biloba or other therapies with anticholinergic effect within 4 weeks of enrolment, or during the study; dementia other than AD, significant neurological disease, major depressive disorder or other major psychiatric disorder.

\section{Study endpoints/outcome measures}

The primary outcome variable was the change in cognitive function from baseline to Week 12, as measured by the 11-item ADAS-Cog (Alzheimer's Disease Assessment Scale-Cognitive Subscale). Secondary outcome measures included change from baseline on global function as measured by Alzheimer's Disease Cooperative Study-Clinical Global Impression of
Change (ADCS-CGIC), cognitive function measured by MMSE and on the computerized cognitive drug research (CDR) test battery, caregiver-reported outcomes and evaluation of the safety and tolerability of AZD3480.

\section{Efficacy assessments}

Appropriately trained and certified raters administered all tests/interviews relating to the assessment of cognitive functions.

The ADAS Cog includes components for memory, language, and praxis and was designed specifically for evaluating the severity of major dysfunctions in cognitive behavior characteristic of patients with $\mathrm{AD}$ [21]. Tests were administered at baseline, at Week 4 and at Week 12 (or at the end of treatment). A summary score, computed across all dimensions of the 11-item ADASCog was used as the primary outcome variable in the statistical analysis. The maximum score is 70 points, a lower score indicating better cognitive function.

Cognitive function was also assessed using MMSE, a commonly used screening tool for cognitive performance [22]. Tests were administered at enrolment and at the end of treatment (Week 12).

ADCS-CGIC, a standardized rating method, provides a semi-structured format allowing clinicians to gather the necessary information from both $\mathrm{AD}$ patients and caregivers to form a clinical global impression of change [23]. Change from baseline was assessed at the end of treatment (Week 12). The ADCS-CGIC rater was blinded to all other assessments during the study. 
Caregivers completed the following instruments at baseline and at Week 12 (end of treatment): Disability Assessment for Dementia (DAD [24, 25]), Zarit Burden Interview (ZBI [26-29]), Cohen-Mansfield Agitation Inventory (CMAI-long form with expanded definitions [30]), and Activity and Affect Indicators of Quality of Life (AAIQOL [31]).

The CDR computerized test battery was used in this study in parallel with the established measures of cognition to compare its sensitivity in detecting changes in cognition over more established methods. The version used (CDR Ltd, UK) was specifically developed for use with patients suffering from dementia and has been validated extensively [32-34]. The test battery included 11 tests from which composite factors scores were calculated for power of attention, continuity of attention, quality of working memory, quality of episodic memory and speed of memory.

\section{Safety}

Safety was assessed by monitoring adverse events (AEs), blood pressure, pulse rate, and clinical laboratory variables. AEs were coded according to the Medical Dictionary for Regulatory Activities (MedDRA), and were collected from the first administration of study drug until the patient's final visit in the study. Serious AEs were collected from enrolment to the follow-up visit.

\section{Statistical analyses}

Several assumptions and criteria were used for calculating the proof of concept (PoC) analysis sample size. AZD3480 and donepezil superiority over placebo in ADAS-Cog after 12 weeks treatment by moderate and mild $\mathrm{AD}$ respectively was assumed to be: AZD3480, 4 and 3 points; donepezil, 3 and 2 points. The standard deviation was assumed to be 6 points. If any AZD3480 dose group in any of the two sub-populations (moderate and mild $\mathrm{AD}$ ) were statistically significantly superior versus placebo (onesided $p<0.1$ ) and numerically better than donepezil as assessed by mean change from baseline at Week 12 on the 11-item ADAS-Cog the PoC were to be considered as proven. Acceptable probabilities for erroneous conclusions used in calculations were: $10 \%$ for declaring PoC for a placebo-like drug; $6 \%$ for not declaring $\mathrm{PoC}$ for an efficacious drug; and $10 \%$ that donepezil would not be statistically significantly superior to placebo. Assuming a drop-out rate of $10 \%$ after randomiza- tion these assumptions and criteria resulted in a sample size of 525 (336 mild AD and 189 moderate AD).

The full efficacy analysis population included all randomized patients, classified by treatment group, who received at least one dose of study treatment and, for any efficacy variable, had both a valid baseline assessment and at least one valid assessment after randomization. If more than 7 days had elapsed since the last dose of study treatment, an efficacy assessment was regarded as invalid. The last observation carried forward (LOCF) method was used for missing Week 12 data. For individual efficacy variables, the number of patients included in an analysis was dictated by the availability of data for that particular variable.

In the statistical analyses, patients treated with AZD3480 $35 \mathrm{mg}$ and $100 \mathrm{mg}$ were treated as one group (high-exposure group), while those treated with $5 \mathrm{mg}$ and $20 \mathrm{mg}$ were treated as separate treatment groups.

The change from baseline to the end of the randomized treatment period (Week 12) was analyzed with a linear model using analysis of variance (ANOVA) or covariance (ANCOVA). The results were reported as $p$-values, estimates and confidence intervals.

For the PoC efficacy analyses (analysis of ADASCog by AD severity), treatment, country and baseline ADAS-Cog total score were included as explanatory variables in the model. Country was treated as a random effect.

For the combined efficacy analysis of ADAS-Cog (i.e., mild and moderate AD sub-groups combined), the model included treatment, baseline ADAS-Cog total score, country, and severity group as explanatory variables. Country was treated as a random effect while severity group was treated as a fixed effect.

Secondary efficacy variables were analyzed using ANCOVA models, following the same conventions as the PoC analysis and the combined analysis of ADAS$\mathrm{Cog}$. This article focuses on results from analyses combining the mild and moderate subpopulations.

A post-hoc analysis was undertaken excluding patients with very mild AD (baseline MMSE 25-26). This was based on expert opinion received during the course of the trial. This analysis included 452 patients.

\section{RESULTS}

A total of 659 patients with mild-to-moderate AD (MMSE 12-26) were enrolled into the study and 567 received randomized treatment. The majority of 
patients who were enrolled into the study but subsequently not randomized was as a result of abnormal laboratory data, ECG or disallowed medication use (exclusion criteria of the study). Of the randomized patients, 506 completed the study, with similar rates of completion across the treatment groups (Fig. 2).

Overall, $61(10.8 \%)$ patients discontinued treatment: 20 (8.2\%) AZD3480-treated patients, 19 (11.6\%) placebo-treated patients, and $22(13.8 \%)$ donepeziltreated patients. There was no apparent dose-related pattern of discontinuations among the AZD3480 patients. The most common primary reasons for withdrawal from treatment were AEs (23 patients, 4.0\%) and voluntary discontinuation (23 patients, $4.0 \%$ ).

Baseline demographic variables and disease characteristics are summarized for all patients in Table 1. The majority of patients were white (99\%), and $63 \%$ were female. The mean age was 74 years and the mean BMI $25.7 \mathrm{~kg} / \mathrm{m}^{2}$. Forty-four percent of patients were categorized as RMs. Per the design, the majority of patients (61\%) had a baseline MMSE score of between 21 and 26, categorizing them as having mild $\mathrm{AD} ; 16 \%$ of patients had very mild AD (MMSE 25-26). The mean MMSE score at baseline was $21(\mathrm{SD} \pm 3.7)$. Most patients had been diagnosed with $\mathrm{AD}$ within the previous year and $87 \%$ were treatment naive.

Baseline demographics and disease characteristics were generally well-balanced across individual treatment groups.

\section{Efficacy}

Of 567 patients who received treatment, 558 were included in the full analysis set according to criteria described in the Statistical analyses section. Data from these patients, where available, were included in the individual analyses of each efficacy variable.

\section{1-item ADAS-Cog}

The combined analysis of change from baseline in ADAS-Cog total score at Week 12 (LOCF) is shown in Table 2. Negative differences indicate an improvement. LS mean changes from baseline at Week 12 were not statistically significantly superior to placebo for any of the AZD3480 dose groups. This was also the case

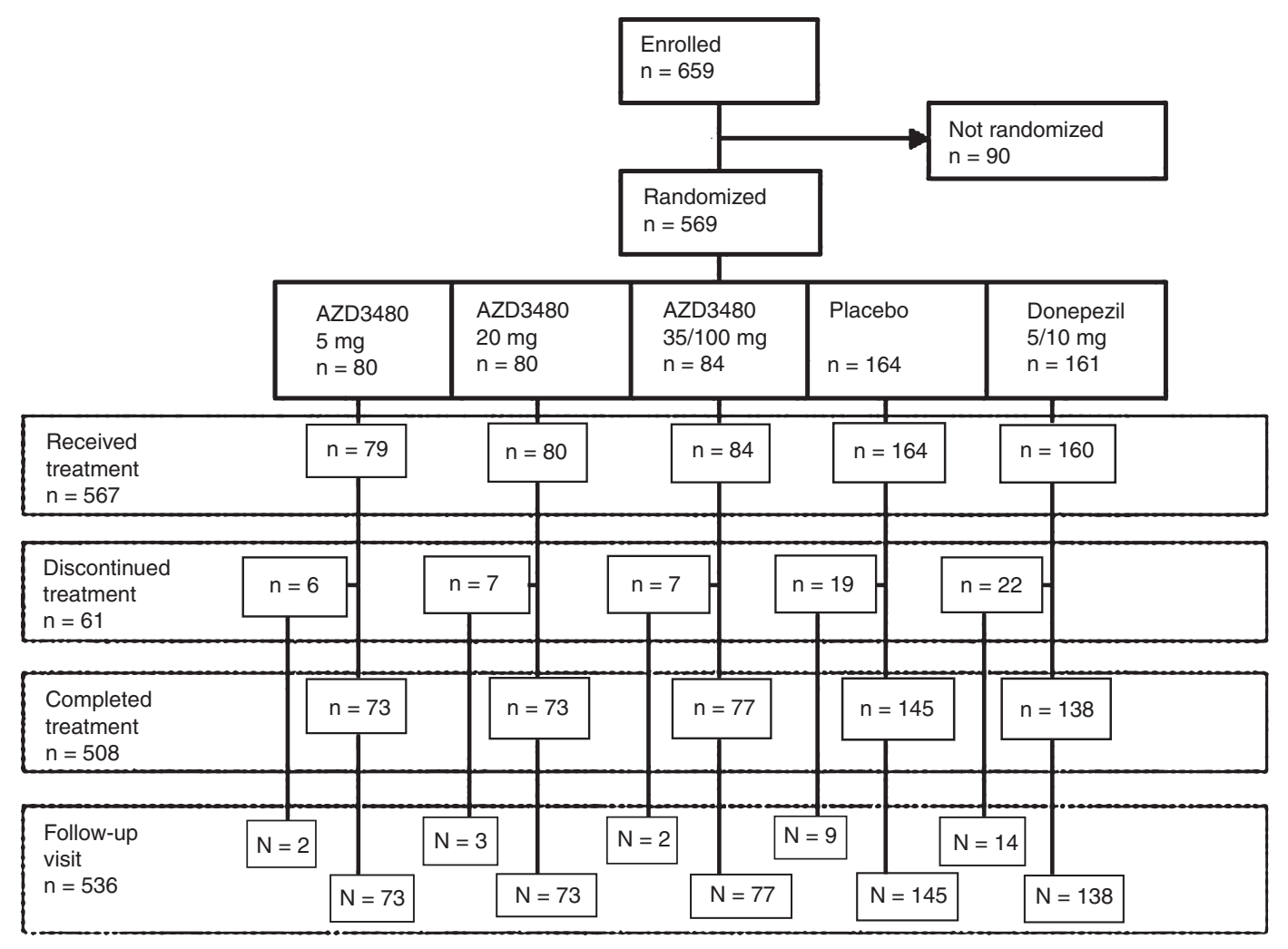

Fig. 2. Patient disposition. 
Table 1

Baseline patient demographics

\begin{tabular}{|c|c|c|c|c|c|c|c|}
\hline & \multicolumn{3}{|c|}{ AZD3480 } & \multirow{2}{*}{$\begin{array}{l}\text { Placebo } \\
(n=163)\end{array}$} & \multirow{2}{*}{$\begin{array}{c}\text { Donepezil } \\
5 / 10 \mathrm{mg} \\
(n=158)\end{array}$} & \multirow{2}{*}{$\begin{array}{c}\text { Total } \\
(n=558)\end{array}$} \\
\hline & & $\begin{array}{c}5 \mathrm{mg} \\
(n=77)\end{array}$ & $\begin{array}{l}20 \mathrm{mg} \\
(n=78)\end{array}$ & $\begin{array}{c}35 / 100 \mathrm{mg} \\
(n=82)\end{array}$ & & & \\
\hline Age & Mean (SD) & $74.0(6.01)$ & $73.8(6.51)$ & $72.7(6.24)$ & $73.5(6.42)$ & $73.9(6.48)$ & $73.6(6.36)$ \\
\hline \multirow[t]{2}{*}{ Gender } & Male & 23 (29.9) & $28(35.9)$ & $27(32.9)$ & $73(44.8)$ & $54(34.2)$ & $205(36.7)$ \\
\hline & Female & $54(70.1)$ & $50(64.1)$ & $55(67.1)$ & $90(55.2)$ & $104(65.8)$ & $353(63.3)$ \\
\hline \multirow[t]{3}{*}{ Race } & White & $77(100.0)$ & $77(98.7)$ & $81(98.8)$ & $162(99.4)$ & $158(100.0)$ & $555(99.5)$ \\
\hline & Black & 0 & $1(1.3)$ & $1(1.2)$ & 0 & 0 & $2(0.4)$ \\
\hline & Asian & 0 & 0 & 0 & $1(0.6)$ & 0 & $1(0.2)$ \\
\hline \multirow{3}{*}{$\begin{array}{l}\text { CYP2D6 metabolic } \\
\text { capacity } n(\%)\end{array}$} & Unknown* & 0 & $1(1.3)$ & $1(1.2)$ & $4(2.5)$ & $7(4.4)$ & $13(2.3)$ \\
\hline & Rapid & $28(36.4)$ & $29(37.2)$ & $39(47.6)$ & $76(46.6)$ & $71(44.9)$ & $243(43.5)$ \\
\hline & Slow & $49(63.6)$ & $48(61.5)$ & $42(51.2)$ & $83(50.9)$ & $80(50.6)$ & $302(54.1)$ \\
\hline BMI $\left(\mathrm{kg} / \mathrm{m}^{2}\right)$ & Mean (SD) & $26.31(4.45)$ & $25.04(3.34)$ & $25.09(3.77)$ & $26.09(3.83)$ & $25.7(3.29)$ & $25.7(3.72)$ \\
\hline \multirow{2}{*}{$\begin{array}{l}\text { MMSE severity } \\
\text { category } n(\%)\end{array}$} & Mild 21-26 & $46(59.7)$ & $46(59.0)$ & $50(61.0)$ & $99(60.7)$ & $97(61.4)$ & $338(60.6)$ \\
\hline & Moderate $12-20$ & $31(40.3)$ & $32(41.0)$ & $32(39.0)$ & $64(39.3)$ & $61(38.6)$ & $220(39.4)$ \\
\hline Years since AD diagnosis & Mean (SD) & $0.81(1.246)$ & $0.74(1.074)$ & $0.70(1.085)$ & $0.83(1.481)$ & $0.85(1.194)$ & $0.80(1.259)$ \\
\hline \multirow{2}{*}{$\begin{array}{l}\text { Previously treated } \mathrm{AD}^{\#} \\
\quad n(\%)\end{array}$} & No & $63(81.8)$ & $71(91.0)$ & $70(85.4)$ & $145(89.0)$ & $137(86.7)$ & $486(87.1)$ \\
\hline & Yes & $14(18.2)$ & $7(9.0)$ & $12(14.6)$ & $18(11.0)$ & $21(13.3)$ & $72(12.9)$ \\
\hline
\end{tabular}

* If CYP2D6 genotype was unavailable by the time of Visit 4, the patient was treated as a slow metabolizer for the purpose of drug administration only.

\# Previously treated with acetycholinesterase inhibitors or memantine.

Table 2

ADAS-Cog 11-item total score: Change from baseline versus placebo at Week 12 (LOCF)

\begin{tabular}{|c|c|c|c|c|c|c|c|}
\hline \multirow[t]{2}{*}{ Treatment } & \multirow[t]{2}{*}{$n$} & \multirow{2}{*}{$\begin{array}{c}\text { Mean baseline } \\
\text { value (SE) }\end{array}$} & \multicolumn{2}{|c|}{ Change from baseline } & \multicolumn{3}{|c|}{ Difference versus Placebo } \\
\hline & & & LS Mean (SE) & $95 \% \mathrm{CI}$ & LS Mean (SE) & $95 \% \mathrm{CI}$ & One-sided $p$-value \\
\hline AZD3480 $5 \mathrm{mg}$ & 77 & $22.4(1.02)$ & $0.1(0.60)$ & $-1.1,1.23$ & $0.4(0.73)$ & $-1.0,1.81$ & 0.701 \\
\hline AZD3480 $20 \mathrm{mg}$ & 77 & $22.5(1.08)$ & $-1.0(0.60)$ & $-2.2,0.13$ & $-0.7(0.73)$ & $-2.1,0.73$ & 0.166 \\
\hline AZD3480 35/100 mg & 81 & $22.7(1.12)$ & $0.8(0.58)$ & $-0.4,1.90$ & $1.1(0.72)$ & $-0.3,2.49$ & 0.936 \\
\hline Placebo & 157 & $24.0(0.92)$ & $-0.3(0.42)$ & $-1.2,0.50$ & na & na & na \\
\hline Donepezil 5/10 mg & 153 & $23.8(0.83)$ & $-1.1(0.43)$ & $-1.9,-0.21$ & $-0.7(0.59)$ & $-1.9,0.44$ & 0.111 \\
\hline
\end{tabular}

ADAS-Cog, Alzheimer's Disease Assessment Scale-Cognitive Subscale; LOCF, last observation carried forward; na, not applicable. Negative differences indicate an improvement.

when the mild and moderate AD sub-populations were analyzed separately.

The effect of treatment with donepezil was numerically better than placebo (LS mean difference to placebo of -0.7 [SE 0.59]), but was not statistically significant.

The observed cases and LOCF analyses of change from baseline to Week 12 over time are shown in Fig. 3. Patients treated with AZD3480 $20 \mathrm{mg}$ and those treated with donepezil produced a similar mean improvement from baseline at Week 4 that was still present at Week 12. Patients treated with AZD3480 $5 \mathrm{mg}$ and 35/100 $\mathrm{mg}$ showed no mean improvement at either time point. Patients treated with placebo showed a mean improvement at Week 4 that was similar to those treated with AZD3480 $20 \mathrm{mg}$ and those treated with donepezil. The mean score then showed a decline back towards baseline but without reaching the baseline score.
Sensitivity analyses were performed to identify if any center had very differing results, which might have affected the overall outcome: the results were very variable and no such centers could be identified.

In subgroup analyses by gender, both positive and negative differences from placebo were somewhat larger in females compared with males. However, this may have been driven by severity category imbalances as the female group was more severe on ADAS-Cog. When added as an explanatory factor in the analysis model of total cohort, gender did not explain the variability in ADAS-Cog change in any statistically significant way.

A post-hoc analysis on ADAS-Cog excluding patients with very mild $\mathrm{AD}$ at baseline (MMSE 25-26) resulted in slightly increased estimates of the effect size: $-1.4,95 \%$ CI: $(-3.0 ; 0.2)$ for AZD3480 $20 \mathrm{mg}$, and $-1.0,95 \% \mathrm{CI}:(-2.3 ; 0.3)$ for donepezil (Table 3). 


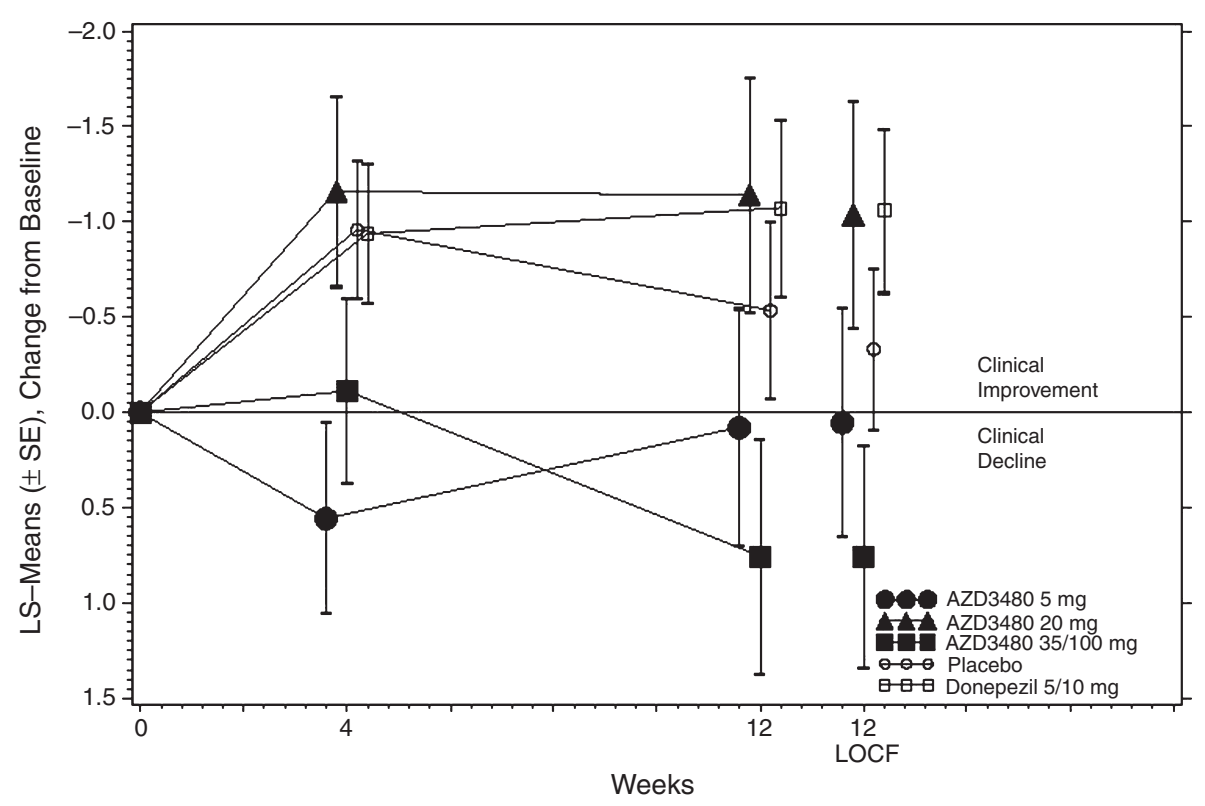

Fig. 3. ADAS-Cog 11-item total score: change from baseline to Week 12: Observed cases and LOCF. ADAS-Cog, Alzheimer's Disease Assessment Scale-Cognitive Subscale; LOCF, last observation carried forward.

Table 3

ADAS-Cog 11-item total score: sub-analysis excluding very mild patients (MMSE 25-26). Change from baseline versus placebo at Week 12 (LOCF)

\begin{tabular}{|c|c|c|c|c|c|c|c|}
\hline \multirow[t]{2}{*}{ Treatment } & \multirow[t]{2}{*}{$n$} & \multirow{2}{*}{$\begin{array}{c}\text { Mean baseline } \\
\text { value (SE) }\end{array}$} & \multicolumn{2}{|c|}{ Change from baseline } & \multicolumn{3}{|c|}{ Difference versus Placebo } \\
\hline & & & LS Mean (SE) & $95 \% \mathrm{CI}$ & LS Mean (SE) & $95 \% \mathrm{CI}$ & One-sided $p$-value \\
\hline AZD3480 $5 \mathrm{mg}$ & 66 & $23.3(9.1)$ & $0.1(0.7)$ & $-1.1,1.4$ & $0.3(0.8)$ & $-1.2,1.9$ & 0.662 \\
\hline AZD3480 $20 \mathrm{mg}$ & 64 & $24.3(9.2)$ & $-1.6(0.7)$ & $-2.9,-0.3$ & $-1.4(0.8)$ & $-3.0,0.2$ & 0.040 \\
\hline AZD3480 35/100 mg & 61 & $25.4(10.0)$ & $0.7(0.7)$ & $-0.7,2.0$ & $0.8(0.8)$ & $-0.8,2.5$ & 0.848 \\
\hline Placebo & 131 & $25.2(11.5)$ & $-0.2(0.5)$ & $-1.1,0.7$ & na & na & na \\
\hline Donepezil 5/10 mg & 130 & $25.4(10.0)$ & $-1.2(0.5)$ & $-2.1,-0.3$ & $-1.0(0.7)$ & $-2.3,0.3$ & 0.065 \\
\hline
\end{tabular}

ADAS-Cog, Alzheimer's Disease Assessment Scale - Cognitive Subscale; LOCF, last observation carried forward; na, not applicable. Negative differences indicate an improvement.

\section{MMSE}

The combined (mild and moderate subgroups) analysis of change in MMSE from baseline at Week 12 (LOCF) is shown in Table 4. Positive scores indicate an improvement. Treatment with AZD3480 $20 \mathrm{mg}$ and $5 \mathrm{mg}$ showed an improvement relative to placebo, as did donepezil treatment (unadjusted $p$-values 0.009 , 0.091 and 0.001 , respectively). AZD3480 35/100 mg treatment showed no improvement relative to placebo.

\section{ADCS-CGIC}

The combined analysis of change in ADCS-CGIC scores from baseline at Week 12 (LOCF) is shown in Table 5. Negative differences indicate an improvement. At Week 12, treatment with AZD3480 $20 \mathrm{mg}$ showed an improvement versus placebo (unadjusted $p$-value <0.001), as did AZD3480 35/100 mg and donepezil treatment (unadjusted $p$-values 0.070 and 0.036 , respectively). The observed percentage of patients rated on the ADCS-CGIC scale as showing improvement (rating = 1 to 3 ) was greater than placebo for all 3 AZD3480 dose groups (AZD3480 range: $35.6 \%$ to $46.7 \%$; placebo $27.7 \%$ ) and was largest for the $20 \mathrm{mg}$ dose (Fig. 4). The corresponding figure for donepezil was $33.3 \%$. The frequency of decline for patients treated with $20 \mathrm{mg}$ AZD3480 was less than placebo whereas the other dose groups were similar to placebo.

\section{$C D R$}

Treatment with AZD3480 did not show any improvement in CDR composite scores in the combined analysis. The variability in composite scores was very high. 
Table 4

MMSE total score: Change from baseline versus placebo at Week 12 (LOCF)

\begin{tabular}{|c|c|c|c|c|c|c|c|}
\hline \multirow[t]{2}{*}{ Treatment } & \multirow[t]{2}{*}{$n$} & \multirow{2}{*}{$\begin{array}{c}\text { Mean baseline } \\
\text { value (SE) }\end{array}$} & \multicolumn{2}{|c|}{ Change from baseline } & \multicolumn{3}{|c|}{ Difference versus Placebo } \\
\hline & & & LS Mean (SE) & $95 \% \mathrm{CI}$ & LS Mean (SE) & $95 \% \mathrm{CI}$ & One-sided $p$-value \\
\hline AZD3480 5 mg & 74 & $20.8(0.40)$ & $0.4(0.35)$ & $-0.3,1.08$ & $0.5(0.38)$ & $-0.2,1.27$ & 0.091 \\
\hline AZD3480 $20 \mathrm{mg}$ & 75 & $20.8(0.41)$ & $0.8(0.35)$ & $0.1,1.47$ & $0.9(0.38)$ & $0.2,1.67$ & 0.009 \\
\hline AZD3480 35/100 mg & 77 & $21.1(0.42)$ & $-0.1(0.35)$ & $-0.8,0.59$ & $0.0(0.38)$ & $-0.7,0.79$ & 0.454 \\
\hline Placebo & 145 & $20.7(0.31)$ & $-0.1(0.28)$ & $-0.7,0.42$ & na & na & na \\
\hline Donepezil 5/10 mg & 138 & $20.6(0.31)$ & $0.9(0.28)$ & $0.4,1.47$ & $1.0(0.32)$ & $0.4,1.68$ & 0.001 \\
\hline
\end{tabular}

MMSE, Mini Mental State Examination; LOCF, last observation carried forward; na, not applicable. Positive scores indicate an improvement.

Table 5

ADCS-CGIC score: Change from baseline at Week 12 (LOCF)

\begin{tabular}{|c|c|c|c|c|c|c|}
\hline \multirow[t]{2}{*}{ Treatment } & \multirow[t]{2}{*}{$n$} & \multicolumn{2}{|c|}{ Rating of change from baseline } & \multicolumn{3}{|c|}{ Difference versus placebo } \\
\hline & & LS Mean (SE) & $95 \% \mathrm{CI}$ & LS Mean (SE) & $95 \% \mathrm{CI}$ & One-sided $p$-value \\
\hline AZD3480 5 mg & 73 & $3.9(0.12)$ & $3.7,4.18$ & $-0.1(0.14)$ & $-0.4,0.18$ & 0.239 \\
\hline AZD3480 $20 \mathrm{mg}$ & 75 & $3.6(0.12)$ & $3.3,3.79$ & $-0.5(0.14)$ & $-0.8,-0.21$ & $<0.001$ \\
\hline AZD3480 35/100 mg & 78 & $3.8(0.12)$ & $3.6,4.07$ & $-0.2(0.14)$ & $-0.5,0.07$ & 0.070 \\
\hline Placebo & 148 & $4.0(0.09)$ & $3.9,4.22$ & na & na & na \\
\hline Donepezil 5/10 mg & 141 & $3.8(0.10)$ & $3.6,4.02$ & $-0.2(0.12)$ & $-0.4,0.02$ & 0.036 \\
\hline
\end{tabular}

ADCS-CGIC, Alzheimer's disease Cooperative Study-Clinical Global Impression of Change; LOCF, last observation carried forward; na, not applicable. Rating scale: $1-3=$ improvement, $4=$ no change, $5-7=$ decline. Negative differences versus placebo indicate an improvement.

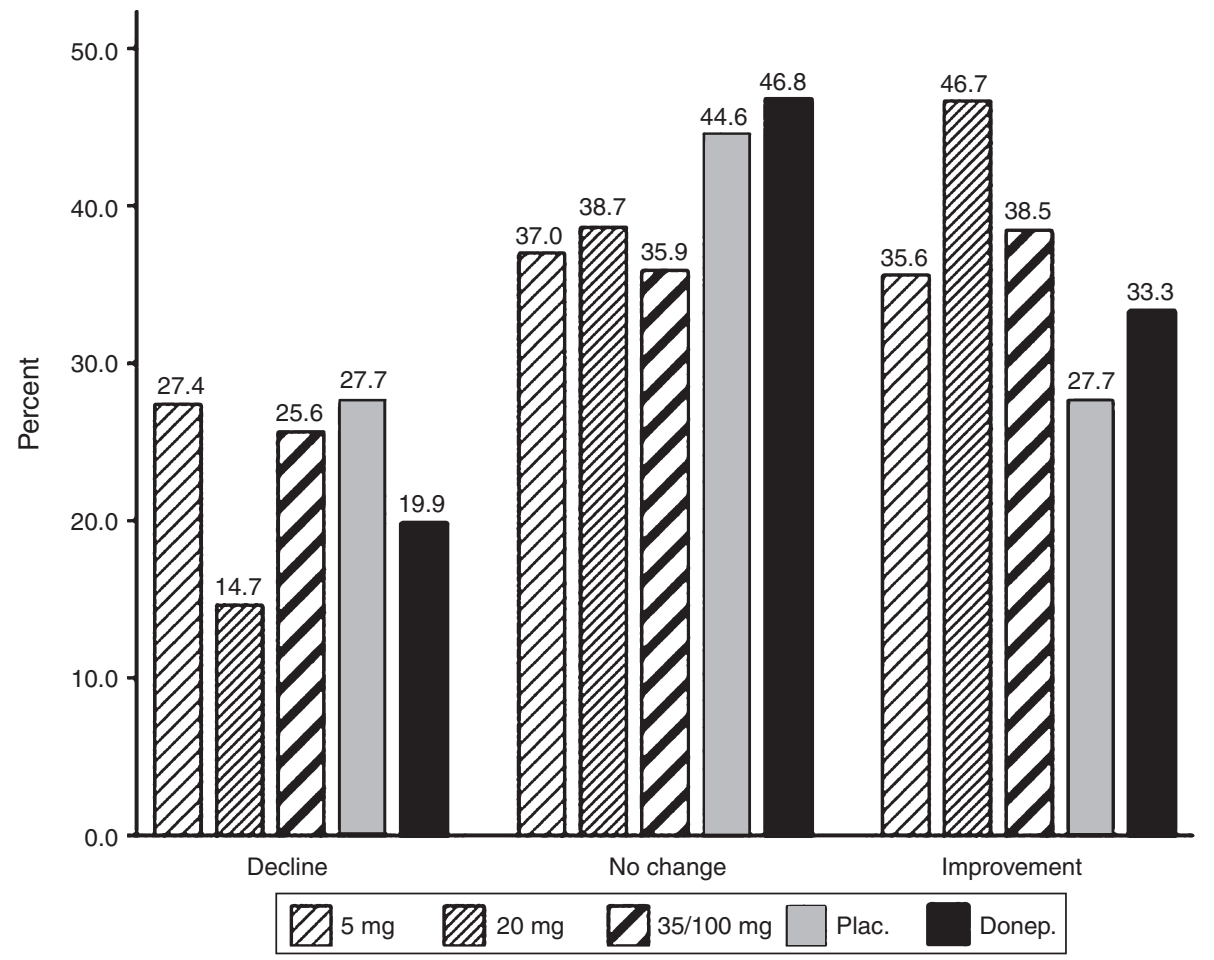

Fig. 4. ADCS-CGIC score: change from baseline at Week 12 (LOCF). ADCS-CGIC, Alzheimer's disease Cooperative Study-Clinical Global Impression of Change; LOCF, last observation carried forward.

\section{Caregiver-reported outcomes}

The combined analysis of change from baseline in DAD total score at Week 12 (LOCF) is shown in Table 6. Positive scores indicate an improvement rela- tive to placebo. Treatment with AZD3480 35/100 mg showed an improvement relative to placebo (unadjusted $p$-value $<0.1$ ), with an LS mean difference of 2.9 (SE 2.15; 95\% CI -1.3, 7.11). Treatment 
Table 6

DAD total score: Change from baseline versus placebo at Week 12 (LOCF)

\begin{tabular}{|c|c|c|c|c|c|c|c|}
\hline \multirow[t]{2}{*}{ Treatment } & \multirow[t]{2}{*}{$n$} & \multirow{2}{*}{$\begin{array}{c}\text { Mean baseline } \\
\text { value (SE) }\end{array}$} & \multicolumn{2}{|c|}{ Change from baseline } & \multicolumn{3}{|c|}{ Difference versus Placebo } \\
\hline & & & LS Mean (SE) & $95 \% \mathrm{CI}$ & LS Mean (SE) & $95 \% \mathrm{CI}$ & One-sided $p$-value \\
\hline AZD34805 mg & 61 & $76.6(2.37)$ & $0.2(1.84)$ & $-3.4,3.80$ & $2.8(2.20)$ & $-1.5,7.13$ & 0.102 \\
\hline AZD3480 $20 \mathrm{mg}$ & 58 & $77.4(2.58)$ & $-1.2(1.89)$ & $-4.9,2.51$ & $1.4(2.24)$ & $-3.0,5.82$ & 0.264 \\
\hline AZD3480 35/100 mg & 66 & $73.4(3.14)$ & $0.3(1.77)$ & $-3.2,3.76$ & $2.9(2.15)$ & $-1.3,7.11$ & 0.090 \\
\hline Placebo & 124 & $74.8(2.17)$ & $-2.6(1.32)$ & $-5.2,-0.02$ & na & na & na \\
\hline Donepezil 5/10 mg & 109 & $71.0(2.41)$ & $-0.8(1.42)$ & $-3.6,2.00$ & $1.8(1.85)$ & $-1.8,5.46$ & 0.164 \\
\hline
\end{tabular}

DAD, Disability Assessment for Dementia; LOCF, last observation carried forward; na, not applicable. Positive scores indicate an improvement.

with AZD3480 $5 \mathrm{mg}$ showed a numerical improvement similar to that seen with $35 / 100 \mathrm{mg}$ (unadjusted $p$-value $=0.102$ ). Treatment with AZD3480 did not show improvement compared with placebo on the CMAI, AAIQOL, or ZBI.

\section{Safety}

The safety population included all patients who received at least one dose of study treatment. In general, few patients reported an $\mathrm{AE}$ for any particular preferred term. The most common AEs (occurring in $\geq 3$ patients among AZD3480 treatment groups or in $\geq 2$ patients in any single treatment group) reported overall were headache, nasopharyngitis, diarrhea, dizziness, and fatigue (Table 7). Incidences in the AZD3480 groups were generally similar to placebo, although those treated with $35 / 100 \mathrm{mg}$ had slightly higher rates than placebo for dizziness $(4.8 \%$ versus $1.2 \%)$ and fatigue $(4.8 \%$ versus $0.6 \%)$. Patients treated with donepezil had slightly higher rates of diarrhea (5.0\% versus $1.8 \%)$ and vomiting $(4.4 \%$ versus $0.6 \%)$ compared with placebo. Most AEs were considered by the investigator to be of mild or moderate intensity. No nicotine withdrawal symptoms were identified.

\section{DISCUSSION}

The primary outcome measure of change from baseline on ADAS-Cog 11-item total score was not statistically significant relative to placebo for either AZD3480 or donepezil. Therefore, donepezil could not establish assay sensitivity and it was not possible to draw any firm conclusions regarding the efficacy of AZD3480 on the ADAS-Cog. A contributory factor could be the large number of centers (84) and countries (10) involved in the trial, which may have increased variability. The observed mean effect of donepezil on ADAS-Cog relative to placebo was certainly lower than predicted and this suggests that the study may have

Table 7

Most common AEs* to end of treatment

\begin{tabular}{|c|c|c|c|c|c|c|}
\hline \multirow[t]{2}{*}{ Preferred term } & \multicolumn{3}{|c|}{ AZD3480 } & \multirow{2}{*}{$\begin{array}{c}\text { Placebo } \\
(n=164) \\
n(\%)\end{array}$} & \multirow{2}{*}{$\begin{array}{c}\text { Donepezil } \\
5 / 10 \mathrm{mg}(n=160) \\
n(\%)\end{array}$} & \multirow{2}{*}{$\begin{array}{c}\text { Total } \\
(n=567) \\
n(\%)\end{array}$} \\
\hline & $\begin{array}{c}5 \mathrm{mg}(n=79) \\
n(\%)\end{array}$ & $\begin{array}{c}20 \mathrm{mg}(n=80) \\
n(\%)\end{array}$ & $\begin{array}{c}35 / 100 \mathrm{mg}(n=84) \\
n(\%)\end{array}$ & & & \\
\hline Patients with any AE & $21(26.6)$ & $23(28.8)$ & $34(40.5)$ & $60(36.6)$ & $60(37.5)$ & $198(34.9)$ \\
\hline Headache & $3(3.8)$ & $2(2.5)$ & $4(4.8)$ & $9(5.5)$ & $5(3.1)$ & $23(4.1)$ \\
\hline Nasopharyngitis & $1(1.3)$ & $2(2.5)$ & $2(2.4)$ & $9(5.5)$ & $3(1.9)$ & $17(3.0)$ \\
\hline Diarrhea & $1(1.3)$ & $2(2.5)$ & $1(1.2)$ & $3(1.8)$ & $8(5.0)$ & $15(2.6)$ \\
\hline Dizziness & $2(2.5)$ & $2(2.5)$ & $4(4.8)$ & $2(1.2)$ & $5(3.1)$ & $15(2.6)$ \\
\hline Fatigue & $1(1.3)$ & $1(1.3)$ & $4(4.8)$ & $1(0.6)$ & $4(2.5)$ & $11(1.9)$ \\
\hline Insomnia & 0 & 0 & $2(2.4)$ & $3(1.8)$ & $6(3.8)$ & $11(1.9)$ \\
\hline Nausea & 0 & 0 & $2(2.4)$ & $2(1.2)$ & $6(3.8)$ & $10(1.8)$ \\
\hline Vomiting & $1(1.3)$ & 0 & $1(1.2)$ & $1(0.6)$ & $7(4.4)$ & $10(1.8)$ \\
\hline Anxiety & 0 & $1(1.3)$ & $1(1.2)$ & $4(2.4)$ & $2(1.3)$ & $8(1.4)$ \\
\hline Arthralgia & $3(3.8)$ & 0 & $2(2.4)$ & $1(0.6)$ & 0 & $6(1.1)$ \\
\hline Back Pain & $1(1.3)$ & 0 & $3(3.6)$ & 0 & $2(1.3)$ & $6(1.1)$ \\
\hline Nightmare & 0 & $1(1.3)$ & $1(1.2)$ & 0 & $4(2.5)$ & $6(1.1)$ \\
\hline Influenza & $1(1.3)$ & 0 & $2(2.4)$ & 0 & $2(1.3)$ & $5(0.9)$ \\
\hline Edema Peripheral & $1(1.3)$ & 0 & $2(2.4)$ & $1(0.6)$ & $1(0.6)$ & $5(0.9)$ \\
\hline Urinary Tract Infection & 0 & $1(1.3)$ & $1(1.2)$ & $1(0.6)$ & $2(1.3)$ & $5(0.9)$ \\
\hline Blood Pressure Increased & $1(1.3)$ & 0 & $1(1.2)$ & 0 & $2(1.3)$ & $4(0.7)$ \\
\hline Urinary Incontinence & 0 & $2(2.5)$ & 0 & 0 & $1(0.6)$ & $3(0.5)$ \\
\hline
\end{tabular}

*Defined as $\geq 3$ patients in AZD3480 treatment groups or $\geq 2$ patients in any single treatment group. 
been underpowered. It is possible that a longer duration of treatment e.g., 24 weeks may have resulted in assay sensitivity with donepezil. However, the power in our study was based on the mean -2.7 points reported in the registration trial over 12 weeks $10 \mathrm{mg} /$ day donepezil treatment [35], and the weighted mean difference of -2.98 (LOCF, 12 week studies) or -2.45 (12 week completers) reported in the Cochrane metaanalysis for $10 \mathrm{mg} /$ day donepezil [36]. Other recent studies of investigational drugs which have included donepezil as a control have also reported relatively small effects on ADAS-Cog $(-0.8$ and -1.2 respectively) compared with what had been reported in earlier studies, even when the treatment period was 24 weeks [37, 38]. One important difference between recent studies and studies conducted with donepezil in the 1990s is the availability today of a number of approved drugs for the symptomatic treatment of $\mathrm{AD}$ which may affect the type of patients selected for placebocontrolled clinical trials. However, $87 \%$ of patients in this study had not been previously treated with acetylcholinesterase inhibitors or memantine. It is likely that a proportion were comparable to patients studied in the 1990s since some were recruited from countries where access to acetylcholinesterase inhibitors and memantine is difficult. The small effect of donepezil in the present study may in part be because the improvement in the placebo group had not declined back to baseline by 12 weeks. It may also be due to the relatively mild severity of patients (mean MMSE 21) compared with those that were included in earlier studies (mean MMSE 19) [35, 39].

A post-hoc analysis excluding very mild patients (MMSE 25-26) did increase the effect of donepezil and the effect of the AZD3480 $20 \mathrm{mg}$ dose. This may be due to improved diagnostic certainty, especially given the mean time since diagnosis was relatively short ( 0.8 years). It may also be due to the increased sensitivity of the ADAS-Cog as the severity of the cohort increases [40].

The CDR test battery did not offer any advantages over ADAS-Cog in this study in detecting an effect of AZD3480. However, the variability in composite scores was very high which could have masked any potential gain. This may indicate difficulties in applying this measure to a large multicentre multinational trial compared with a small number of highly practiced centers. Improvements in several secondary outcome measures (MMSE, ADCS-CGIC, DAD) were observed for AZD3480, especially for the $20 \mathrm{mg}$ dose. It is possible that these scales are capturing an effect such as an improvement in function or behavior that is not seen on the more specific assessments of cognition like the ADAS-Cog. This suggests that stimulation of $\alpha 4 \beta 2$ nicotinic receptors might be having some effects on outcomes relevant to AD although the dose response relationship is puzzling. Further studies will be required to test this. Interestingly, a recent study with AZD3480 in adults with attention-deficit hyperactivity disorder (ADHD) showed improvements with a $50 \mathrm{mg}$ dose in clinical symptoms measured on the Conners' Adult ADHD Rating Scale-Investigator Rating (CAARS-INV) and on a core cognitive deficit for ADHD indicating effects on cognitive function [41]. However, the relevance of these findings to AD is not known.

The overall safety and tolerability profile for the AZD3480 dose groups was similar to placebo and with fewer gastrointestinal-related adverse events (diarrhea, nausea, and vomiting) than observed with donepezil. The pattern of AEs for donepezil was as expected. No nicotine withdrawal symptoms were identified during the 2-week follow-up period after end of treatment with AZD3480.

In conclusion, the study did not meet its proof of concept criteria. However, as the effect on the primary outcome measure ADAS-Cog was not statistically significant versus placebo for either AZD3480 or the active control donepezil, the study was considered to be inconclusive. Nevertheless, an improvement in several secondary outcome measures was observed with AZD3480 and donepezil, and AZD3480 was well tolerated. There were no signs of any nicotine withdrawal symptoms. Further studies are required to determine the therapeutic potential in $\mathrm{AD}$ of stimulating of the $\alpha 4 \beta 2$ receptor with neuronal nicotinic agonists.

\section{ACKNOWLEDGMENTS}

The study was sponsored by AstraZeneca Ltd.

We thank the patients, their families, and all of the investigators who participated in the Sirocco study. Their contributions were crucial to the smooth running of the study. The Principal Investigators at each center, listed by country, were as follows: Austria: Michael Rainer, Josef Marksteiner/Thomas Walch, Reinhold Schmidt; Belgium: Peter De Deyn (National Coordinating Investigator), Rik Vandenberghe, Peter Soors, Eddy Mulleners; Bulgaria: Paraskeva Stamenova, Penko Shotekov, Stefka Yancheva, Penka Atanassova, Nadezhda Deleva, Temenuzhka Mateva, Hristo Lilovski; Canada: David Patry, Vasavan Nair, Karen Jennifer Ingram, Sharon Cohen, Felix Veloso, 
Ziad Nasreddine, Giovanni Marotta, Emmanuelle Pourcher, Tilak Mendis, Paul Shelton; Czech Republic: Jiri Bilik, Marcela Bolkova Janikova, Klaudia Borzova, Ilona Divacka, Jakub Hort, Ladislav Hosak, Roman Jirak, Jan Knopp, Jiri Konrad, Jaroslav Lestina, Silvia Musilova, Jiri Pisvejc, Pavel Ressner, Jiri Rozkos, Zdenek Solle (National Coordinating Investigator); Vlastimil Tichy, Germany: Lutz Frölich (National Coordinating Investigator), Michael Bauer, Johannes Schröder, H.-J. Gertz, Matthias Riepe, Gunther Karlbauer, Andrea Knippert, Eike Frahm, Karin Forck-Bödeker, Michael Hüll, Daniel Bittner, Klaus-Christian Steinwachs, Jana Thomsen, Jürgen Ribbschlaeger; Romania: Catalina Tudose, Mirela Manea, Elena Gherman, Cristian Marinescu, Vasile Chirita, Daniela Vulcu; Russia: Svetlana Gavrilova, Victor Koncevoy, Alexandr Skoromets, Anna Lebedeva, Miroslav Odinak, Sofiy Sluchevskay, Oleg Levin, Elena Strachunskay, Oleg Balunov, Nikolay Neznanov; Spain: Mercedes Boada Rovira, Ramón Reñé Ramírez, Jordi Peña Casanova, Ana Frank García, Angel Luís Montejo González, Miguel Aguilar/Pilar Quilez Ferrer, María Dolores Martínez Lozano, Felix Bermejo Pareja, Ana Espino Ibañez, José Luis Molinuevo, Manuel Fernández Martínez, Camino Sevilla Gómez; United Kingdom: Craig Ritchie, Sanjana Nyatsanza, Naji Tabet, David Wilkinson, Mark Dale, Preeti Pandya.

The ADCS-CGIC was used with permission from the NIA Alzheimer's Disease Cooperative Study (NIA Grant AG 10483).

Authors' disclosures available online (http://www.jalz.com/disclosures/view.php?id=699).

\section{REFERENCES}

[1] Cummings JL (2004) Alzheimer's disease. N Engl J Med 351, 56-67.

[2] Birks J (2006) Cholinesterase inhibitors for Alzheimer's disease. Cochrane Database Syst Rev 1, CD005593.

[3] McShane R, Areosa Sastre A, Minakaran N (2006) Memantine for dementia. Cochrane Database Syst Rev 2, CD003154.

[4] Newhouse P, Potter A, Corwin J (1996) Effects of nicotinic cholinergic agents on cognitive functioning in Alzheimer's and Parkinson's disease. Drug Dev Res 38, 278-289.

[5] Gotti C, Zoli M, Clementi F (2006) Brain nicotinic acetylcholine receptors: native subtypes and their relevance. Trends Pharmacol Sci 27, 482-491.

[6] Levin ED, McClernon FJ, Rezvani AH (2006) Nicotinic effects on cognitive function: behavioral characterization, pharmacological specification and anatomic localization. Psychopharmacology 184, 523-539.

[7] Perry E, Martin-Ruiz C, Lee M, Griffiths M, Johnson M, Piggott M, Haroutunian V, Buxbaum JD, Nasland J, Davis K, Gotti C, Clementi F, Tzartos S, Cohen O, Soreq H, Jaros E,
Perry R, Ballard C, McKeith I, Court J (2000) Nicotinic receptor subtypes in human brain ageing, Alzheimer and Lewy body diseases. Eur J Pharmacol 393, 215-222.

[8] Breese CR, Lee MJ, Adams CE, Sullivan B, Logel J, Gillen KM, Marks MJ, Collins AC, Leonard S (2000) Abnormal regulation of high affinity nicotinic receptors in subjects with schizophrenia. Neuropsychopharmacology 23, 351-364.

[9] Paterson D, Norberg A (2000) Neuronal nicotinic receptors in the human brain. Prog Neurobiol 61, 75-111.

[10] Buccafusco JJ, Letchworth SR, Bencherif M, Lippiello PM (2005) Long-lasting cognitive improvement with nicotinic receptor agonists: mechanisms of pharmacokineticpharmacodynamic discordance. Trends Pharmacol Sci 26, 352-360.

[11] Bohme GA, Letchworth SR, Piot-Grosjean O, Gatto GJ, Obinu M-C, Caldwell WS, Laville M, Brunel P, Pellerin R, Leconte J-P, Genevois-Borella A, Dubedat P, Mazadier M, Pradier L, Bencherif L, Benavides J (2004) In vitro and in vivo characterization of TC-1827, a novel brain $\alpha_{4} \beta_{2}$ nicotinic receptor agonist with pro-cognitive activity. Drug Dev Res 62, 26-40.

[12] Moore WC, Togo J, Smith JS, Doherty JJ, Johnson EC (2008) AZD3480, a selective $\alpha 2 / \alpha 4 \beta 2$ neuronal nicotinic agonist, reverses fimbria fornix lesion. Program No. 329.4/C55, Page 167, 2008 Neuroscience Meeting Planner, Washington, DC: Society for Neuroscience. http://www.sfn. org/skins/main/pdf/abstracts/am2008/poster_presentations/ monday_am.pdf, Accessed on June 14, 2010.

[13] Gatto GJ, Bohme GA, Caldwell WS, Letchworth SR, Traina VM, Obinu MC, Laville M, Reibaud M, Pradier L, Dunbar G, Bencherif M (2004) TC-1734: an orally active neuronal nicotinic acetylcholine receptor modulator with antidepressant, neuroprotective and long-lasting cognitive effects. CNS Drug Rev 10, 147-166.

[14] Gurley D, Robbins AK, Gunyuzlu PL, Moore C, Johnson EC (2008) Differential pharmacology of clinically relevant compounds at the two stoichiometries of the nicotinic $\mathrm{a} 4 \mathrm{~b} 2$ and $\mathrm{a} 2 \mathrm{~b} 2$ receptors. Program No. 329.9/C60, Page 172, 2008 Neuroscience Meeting Planner, Washington, DC: Society for Neuroscience. http://www.sfn. org/skins/main/pdf/abstracts/am2008/poster_presentations/ monday_am.pdf, Accessed on June 14, 2010.

[15] Dunbar GC, Koumenis IL, Kuchibhatla RV, Wamsley JK (2006) Evidence of efficacy for TC-1734 (AZD3480) in the treatment of cognitive impairment in older subjects. 9th Int Geneva/Springfield Symp Adv Alzheimer Ther (April 19-22, Geneva) 2006, Poster. http://media.corporateir.net/media_files/irol/17/178332/GenevaPoster.pdf, Accessed on June 14, 2010.

[16] Dunbar GC, Kuchibhatla R (2006) Cognitive enhancement in man with ispronicline, a nicotinic partial agonist. $J \mathrm{Mol}$ Neurosci 30, 169-172.

[17] Dunbar G, Demazieres A, Monreal A, Cisterni C, Metzger D, Kuchibhatla R, Luthringer R (2006) Pharmacokinetics and safety profile of ispronicline (TC-1734), a new brain nicotinic receptor partial agonist, in young healthy male volunteers. J Clin Pharmacol 46, 715-726.

[18] Dunbar G, Boeijinga PH, Demazieres A, Cisterni C, Kuchibhatla R, Wesnes K, Luthringer R (2007) Effects of TC-1734 (AZD3480), a selective neuronal nicotinic receptor agonist, on cognitive performance and the EEG of young healthy male volunteers. Psychopharmacology 191, 919929.

[19] Dunbar GC, Inglis F, Kuchibhatla R, Sharma T, Tomlinson M, Wamsley J (2007) Effect of ispronicline, a neuronal nicotinic 
acetylcholine receptor partial agonist, in subjects with age associated memory impairment (AAMI). J Psychopharmacol 21, 171-178.

[20] Dunbar G, Kuchibhatla R, Lee G (2010) A randomized double-blind study comparing 25 and $50 \mathrm{mg}$ TC-1734 (AZD3480) with placebo, in older subjects with ageassociated memory impairment. J Psychopharmacol, published online 11 June 2010: 10.1177/0269881110367727.

[21] Rosen WG, Mohs RC, Davis KL (1984) A new rating scale for Alzheimer's Disease. Am J Psychiatry 141, 1356-1364.

[22] Folstein MF, Folstein SE, McHugh PR (1975) "Mini-mental state" A practical method for grading the cognitive state of patients for the clinician. Psychiat Res 12, 189-198.

[23] Schneider LS, Olin JT, Doody RS, Clark CM, Morris JC, Reisberg B, Schmitt FA, Grundman M, Thomas RG, Ferris SH (1977) Validity and reliability of the Alzheimer's Disease Cooperative Study-Clinical Global Impression of Change. Alz. Dis Assoc Disord 11(suppl 2), S22-S32.

[24] Gauthier S, Gelinas I, Gauthier L (1997) Functional disability in Alzheimer's disease. Int Psychogeriatr 9(Suppl 1), 163165 .

[25] Gelinas I, Gauthier L, McIntyre M, Gauthier S (1999) Development of a functional measure for persons with Alzheimer's disease: the disability assessment for dementia. Am J Occup Ther 53, 471-481.

[26] Zarit SH (2002) Caregiver's Burden. In Family and Professional Cares: Findings Lead to Action, Andrieu S, Aquino J-P, eds. Serdi Publisher, Paris, pp. 20-24.

[27] Zarit SH, Reever KE, Bach-Peterson J (1980) Relatives of the impaired elderly: correlates of feelings of burden. Gerontologist 20, 649-654.

[28] Zarit S, Orr NK, Zarit JM (1985) Understanding the stress of caregivers. In The Hidden Victims of Alzheimer's Disease: Families Under Stress. New York University Press, New York, pp. 73-86.

[29] Zarit SH, Todd PA, Zarit JM (1986) Subjective burden of husbands and wives as caregivers: a longitudinal study. Gerontologist 26, 260-266.

[30] Cohen-Mansfield J, Marx MS, Rosenthal AS (1989) A description of agitation in a nursing home. J Gerontol 44 (3), M77-M84.

[31] Albert SM, Castillo-Castenada C, Sano M, Jacobs DM, Marder K, Bell K, Lafleche G, Brandt J, Albert M, Stern Y (1996) Quality of life in patients with Alzheimer's disease as reported by patient proxies. J Amer Geriatrics Soc 44, 1342-1347.
[32] Mohr E, Walker D, Randolph C, Sampson M, Mendis T (1996) Utility of clinical trial batteries in the measurement of Alzheimer's and Huntington's dementia. Int Psychogeriatr 8, 397-411.

[33] Nicholl CG, Lynch S, Kelly CA, White L, Simpson L, Simpson PM, Wesnes K, Pitt BMN (1995) The Cognitive Drug Research computerised assessment system in the evaluation of early dementia - Is speed of the essence? Int J Geriatr Psychiatry 10, 199-206.

[34] Simpson PM, Surmon DJ, Wesnes KA, Wilcock GR (1991) The cognitive drug research computerised assessment system for demented subjects: a validation study. Int J Geriatr Psychiatry 6, 95-102.

[35] Rogers SL, Doody RS, Mohs RC, Friedhoff LT, and the Donepezil Study Group (1998a) Donepezil improves cognition and global function in Alzheimer disease. Arch Intern Med 158, 1021-1031.

[36] Birks J, Harvey RJ (2006) Donepezil for dementia due to Alzheimer's disease. Cochrane Database Syst Rev 1, CD001190. DOI:10.1002/14651858.CD001190.pub2

[37] Maher-Edwards G, Dixon R, Hunter J, Gold M, Hopton G, Hunter J, Williams P (2008) Efficacy and tolerability of SB742457, a novel 5HT6 receptor antagonist, and Donepezil in subjects with mild-to-moderate Alzheimer's disease (AD). Alzheimers Dement 4, T772-T773.

[38] Gold M, Alderton C, Zvartau-Hind M, Ritchie S, Saunders A, Craft S, Landreth G, Linnamägi U, Sawchak S (2009) Effects of rosiglitazone as monotherapy in APOE4-stratified subjects with mild-to-moderate Alzheimer's disease. Alzheimers Dement 5, 86

[39] Rogers SL, Farlow MR, Doody RS, Mohs R, Friedhoff LT, and the Donepezil Study Group (1998b) A 24-week, doubleblind, placebo-controlled trial of donepezil in patients with Alzheimer's disease. Neurology 50, 136-145.

[40] Harrison J, Minassian SL, Jenkins L, Black RS, Koller M, Grundman M (2007) A neuropsychological test battery for use in Alzheimer disease clinical trials. Arch Neurol 64, 13231329 .

[41] Mazzulla EC, Potter A, Wilkins H, Dunbar G, Bencherif M, Newhouse P (2009) Novel neuronal $\alpha 4 \beta 2$ nicotinic agonist (AZD3480) effects on behavioral inhibition in adult ADHD. Society for NeuroScience: Annual meeting, Abstract 871.7/DD23 (page 771). http://www.sfn. org/skins/main/pdf/abstracts/am2009/poster_presentations/ PosterPresentation_WedPM.pdf, Accessed on June 14, 2010. 